\title{
OS PRIMEIROS ANOS DO INSTITUTO HISTÓRICO E GEOGRÁFICO DO PARANÁ (1900-1930) ${ }^{1}$
}

\author{
Larissa Rosevics ${ }^{2}$
}

- Enviado em 27/01/2016

- Aprovado em 30/05/2016

\section{RESUMO}

O Instituto Histórico e Geográfico do Paraná (IHGP) foi fundado em 1900, a partir das conjunturas político-econômica e sociocultural presentes no Paraná do início do século XX que buscavam, dentre outros objetivos, construir um imaginário regional capaz de integrar os milhares de imigrantes recém-chegados da Europa à sociedade paranaense. A partir da perspectiva do imaginário social de Cornelius Castoriadis (1982), os objetivos do artigo são refletir sobre a fundação do IHGP, a partir do seu estatuto, e apresentar um histórico dos seus trinta primeiros anos de existência.

Palavras-chave: IHGP, imaginário regional, século XX.

\section{INTRODUÇÃO}

A fundação do Instituto Histórico e Geográfico do Paraná (IHGP) ${ }^{3}$, realizada no dia 24 de maio de 1900, foi realizada como parte das celebrações paranaenses do quarto centenário do Descobrimento do Brasil. Para a cerimônia de fundação, coordenada por Romário Martins, foram convidadas a compareceram à biblioteca do Clube Curitibano dezesseis personalidades ilustres da sociedade paranaense do período ${ }^{4}$.

\footnotetext{
${ }^{1}$ O texto do artigo faz parte da Dissertação da autora, realizada sob a orientação da Professora Dra. Maria Tarcisa Silva Bega e defendida no dia 17 de agosto de 2009. A versão completa está disponível na Biblioteca Digital da UFPR http://dspace.c3sl.ufpr.br:8080/dspace/handle/1884/20195

${ }^{2}$ Graduada em Relações Internacionais (UniCuritiba), Mestre em Sociologia (UFPR) e Doutora em Economia Política Internacional (UFRJ). Professora de Relações Internacionais da Universidade Católica de Petrópolis (UCP). E-mail: larissa.rosevics@gmail.com

${ }^{3}$ A grafia original do IHGP, encontrada nos primeiros documentos é "Instituto Histórico e Geographico Paranaense", conforme utilizado na Dissertação. Contudo, para o artigo, optou-se pela versão atualizada do nome da instituição.

${ }^{4}$ Foram convidados por carta: Dario Velloso, Dr. Sebastião Paraná, General J.B. Bormann, Coronel Jocelyu Borba, Dr. Candido de Abreu, Julio Pernetta, Dr. Ferreira Correia, Nestor de Castro, Dr. Camillo Vanzolini, Capitão José Muricy, Lucio Pereira, Dr. Ermelino de Leão, Dr. Bento Fernandes de Barros e Dr. Emiliano Pernetta. (DOCUMENTOS DO IHGP)
} 
Durante os trinta anos que se seguiram desde a sua fundação, por vezes o IHGP ficou a beira do esquecimento. Sem recursos financeiros, sede própria, reuniões e tampouco publicações regulares, a importância do IHGP inscreve-se no retrato que ele constrói e que expressa, através de seus membros e de suas publicações, da sociedade paranaense do período.

As instituições que surgiram no Paraná no início do século XX, como o IHGP e a Universidade do Paraná (fundada em 1912), exerceram um papel importante como ambientes de discussão e de legitimação do imaginário que se constituía sobre o estado e sobre seus indivíduos.

A produção de símbolos relacionados ao Paraná, enquanto unidade sócio-política, e ao "homem paranaense", foi intensa nesse período, conforme demonstram os trabalhos sobre o Paranismo ${ }^{5}$. Como destaca Cornelius Castoriadis (1982), os estudos sobre instituições precisam basear-se no modo como elas se instituem, o simbólico, e a quê elas servem, o imaginário. O imaginário e o simbólico estão interligados, em que o primeiro se utiliza o segundo para se expressar e existir. Castoriadis (1982, p.13) define como imaginário a "[...] criação incessante e essencialmente indeterminada (social-histórica e psíquica) de figuras/formas/imagens, a partir das quais somente é possível falar-se de 'alguma coisa'. Aquilo que denominamos 'realidade' e 'racionalidade' são seus produtos". Mais do que isso, como destaca Miguel Rojas Mix (2006), o imaginário cria e utiliza imagens para informar, convencer, seduzir e legitimar processos, assim como é um arquivo social em transformação. Ao mesmo tempo em que ele constrói uma identidade e uma realidade, ele tem a capacidade de transformá-la.

Com relação à identidade paranaense, existe uma série de elementos simbólicos que se formaram no imaginário social no período da Primeira República e que envolvem os campos da literatura, das artes plásticas, do jornalismo e da história e que foram elaborados por intelectuais, artistas e políticos ligados aos grupos dominantes do período.

Sobre a relação entre a construção de símbolos e as relações com os grupos dominantes, são necessárias duas ressalvas:

A primeira é que seria limitado afirmar que a arte paranaense, ao construir ou representar símbolos de uma identidade paranaense com a qual a sociedade posteriormente se identificou, tenha sido forjada para servir aos interesses dos grupos dominantes. É necessário levar em consideração a liberdade criativa e imaginativa dos seus artistas, conforme destaca Salturi ( 2007).

\footnotetext{
${ }^{5} \mathrm{O}$ Paranismo foi um processo político-cultural que existiu no Paraná durante a Primeira República e que procurou construir as bases para uma identidade paranaense e para a coesão do grupo social que vivia no estado. Foi a partir dele que surgiu o movimento paranista, desenvolvido por artistas e intelectuais na década de 20 e que instituíram algumas características ao imaginário paranaense, tais como o pinheiro e o pinhão como símbolos, o imigrante valoroso como tipo ideal e o estado como modelo de futuro para a nação. Sobre o Paranismo, ver: KEINERT, 1978; TRINDADE, 1997; PEREIRA, 1998; SALTURI, 2007; CAMARGO, 2007.
} 
No entanto, tais obras ultrapassaram os seus significados artísticos e assumiram um papel de representação do Paraná, com o qual os grupos sociais heterogêneos que o compunha puderam se identificar, contribuindo para a formação do imaginário do estado, segundo os interesses dos grupos dominantes.

A segunda ressalva refere-se ao papel dos intelectuais e artistas nesse processo, uma vez que se entende que eles são indivíduos que pertencem há um tempo e que estão engajados com os projetos, as ideias e os valores que os cercam.

No caso dos intelectuais e artistas paranaenses do início do século, a proximidade com as ideias nacionalistas oitocentistas e com o romantismo contribuiu para as escolhas estéticas e temáticas de suas obras. Além disso, as concepções eugenistas presentes no Brasil do início do século, exploradas por Lilian Shwarcz (2005), também influenciaram na exaltação do homem branco europeu como a origem do novo paranaense, em detrimento das comunidades indígenas e afrodescendentes existentes no estado. Cultura e política compartilham uma linha tênue que envolve história, processos sociais, movimentos políticos e culturais.

A partir de Castoriadis é possível afirmar que o ponto de partida dos estudos sobre instituições, como o IHGP, deve basear-se na maneira sob a qual essas instituições se constituíram, ou seja, o simbólico:

As instituições não se reduzem ao simbólico, mas elas só podem existir no simbólico, são impossíveis fora de um simbólico em segundo grau e constituem cada qual sua rede simbólica. Uma organização dada da economia, um sistema de direito, um poder instituído, uma religião existem socialmente como sistemas simbólicos sancionados. Eles consistem em ligar a símbolos (a significantes) significados (representações, ordens, injunções ou incitações para fazer ou não fazer, consequências, - significações no sentido amplo do termo) e fazê-los valer como tais, ou seja, a tornar esta ligação mais ou menos forçosa para a sociedade ou o grupo considerado. (1982, p.13)

As instituições sociais de que trata Cartoriais são instituídas ao mesmo tempo em que instituem, ou seja, são objetivas e racionais ao mesmo tempo em que são imaginárias e simbólicas. Se elas podem padronizar valores, costumes ou práticas coletivas é porque elas foram instituídas a partir de certos valores, costumes ou práticas coletivas. Portanto, elas só podem existir no simbólico, pois ele é o único capaz de lhes dar sentido e de tornar suas ações legítimas. Os sistemas simbólicos dos quais elas são compostas, são aqueles capazes de ligar os símbolos aos seus significados de maneira que possa ser reconhecidos pela coletividade à qual pertencem e para a qual fazem sentido.

Esses sistemas simbólicos são constituídos no interior do imaginário de cada sociedade, a partir das estruturas imagéticas pré-existentes e as suas relações com o contexto histórico e social vigente. Ou seja, os 
símbolos e seus significados, bem como todo sistema simbólico que permite a constituição de uma instituição, estão fundados no imaginário, formado por imagens mentais e materiais pertencentes ao real e ao histórico de cada sociedade a partir das suas necessidades.

A partir do momento em que são instituídas, as instituições adquirem a capacidade de transformar ou até mesmo fundar imaginários. Por exemplo, com relação ao significante, as instituições podem, por vezes, fazer com que ele ultrapasse a ligação que tem com o significado, conduzindo a novos outros significados. São a história e a sociedade agindo sobre suas próprias edificações simbólicas, pois, sendo elas aquelas que possibilitam a constituição de todo e qualquer simbolismo, são também suas transformações capazes de conduzir a novas significações através de aparelhos de Estado, como as instituições.

A partir das considerações enunciadas, o objetivo do artigo é apresentar os elementos que compõem a fundação do IHGP, como seus membros e seu estatuto, bem como fazer uma reflexão sobre os seus trinta primeiros anos de existência.

\section{OS INSTITUTOS HISTÓRICOS E A FORMAÇÃO DOS IMAGINÁRIOS}

O IHGP está inserido no contexto dos regionalismos da Primeira República, que buscaram criar particularidades aos estados da federação, a partir do projeto maior da nação brasileira. Inspirado no Instituto Histórico e Geográfico Brasileiro (IHGB), fundado em 1838, o IHGP manteve intenso contato com a instituição nacional, compartilhando ideais, membros e pesquisas.

Ambas as instituições tiveram inspiração no francês Institut Historique de Paris, de quem herdaram o projeto civilizador de progresso, de nação e de unidade nacional. Fundado em 1834, o objetivo da instituição parisiense era formar a História Oficial da França. Tal objetivo possibilitou a concentração na capital Paris do maior volume de informações sobre as diversas partes do país, com o discurso do controle e manutenção da ordem (GUIMARÃES, 1988).

No Paraná não foi diferente. O IHGP, assim como as demais instituições do período e o próprio Paranismo, teve a capital Curitiba como o centro das informações sobre as diversas regiões do estado e irradiador de uma identidade unitária aos seus grupos populacionais. Assim, a partir da capital, foi possível o controle físico e social do Paraná. 
Estas instituições foram fundadas com fins científicos, pensadas e constituídas a partir da sociedade civil. No entanto, no Brasil entre os séculos XIX e XX, os membros dos institutos eram em grande parte membros dos grupos dominantes da sociedade e havia um diálogo intenso entre os interesses do Estado e a produção das instituições.

No ano de 1827, cinco anos depois da proclamação da independência, surgiu no Rio de Janeiro a Sociedade Auxiliadora da Indústria Nacional (SAIN). Composta por militares, nobres e políticos, a instituição tinha como objetivo fomentar a industrialização do país, através da ideia iluminista de progresso. Foi desse espírito progressista que, no seu interior, segundo Manoel Luís Salgado Guimarães (1988), surgiu à ideia do IHGB, voltado para a construção de um passado para a nação, uma alternativa à integração do país, e buscando à centralização das informações sobre as diversas regiões na capital do Império e sede da instituição, o Rio de Janeiro. Seus estatutos, ao longo do período imperial, procuraram estabelecer as principais diretrizes para a formação da História Nacional, que envolviam desde uma metodologia de coleta, seleção e organização de dados e documentos, até a elaboração de revistas e livros para divulgação.

A partir das suas relações com o governo central, aos poucos a História Nacional construída pelo Instituto tornou-se a História Oficial do Brasil, sendo publicada em livros didáticos e divulgada pelo país através do sistema educacional. Logo após a sua fundação, o IHGB passou a ser financiado pelo Império e apadrinhado pelo Imperador. "Cinco anos após a sua fundação, as verbas do Estado Imperial já representavam 75\% do orçamento do IHGB" (GUIMARÃES, 1988, p.9). Os interesses da coroa brasileira influenciaram a seleção e o desenvolvimento das pesquisas produzidas pelo IHGB, bem como tornou a história produzida pelo Instituto como a História Nacional Oficial do país, sendo o Estado-nação o centro de toda a produção do Instituto em seus primeiros anos de existência.

Ainda que não houvesse a intenção de transformar o discurso produzido pela instituição em oficial, o fato é que, no recém-fundado Colégio Dom Pedro II, muitos de seus professores eram membros do Instituto, pois, “[...] ser professor de uma instituição tão sólida e renomada era sinônimo de competência intelectual, não apenas nos anos imediatamente posteriores à fundação, mas durante todo o período estudado. Muitas vezes, o trabalho junto ao magistério serviu como ponte para a confecção de obras didáticas [...]" (CALLARI, 2001, p.68). Na concepção dos intelectuais da época, a educação era caracterizada como o processo civilizador aos quais os jovens brasileiros necessitavam passar, e a História Nacional promovida pelo IHGB fazia parte da construção da consciência cívica e do imaginário nacional. Como escreveu Lília Schwarcz (2001, p.99):

Criado logo após a independência política do país, o estabelecimento carioca [IHGB] cumpria o papel que lhe fora reservado, assim como aos demais institutos históricos: 
construir uma história da nação, recriar um passado, solidificar mitos de fundação, ordenar fatos buscando homogeneidades em personagens e eventos até então dispersos. [...] unificar a nação significava a construção de um passado que se pretendia singular, embora claramente marcado pelo perfil dos influentes grupos econômicos e sociais que participavam dos diversos institutos. Com uma composição social semelhante à das academias ilustradas europeias, onde os sócios eram escolhidos antes de tudo por suas relações sociais, os diferentes centros produziram falas marcadamente regionais, apesar da pretensão totalizante.

\section{O ESTATUTO DO IHGP}

O instrumento normativo que estabelece as diretrizes do IHGP é o seu estatuto. Aprovado em Assembleia Geral no dia 3 de julho de 1900, data do início oficial de suas atividades, teve como redatores uma comissão formada pelos membros fundadores Romário Martins, o italiano Camillo Vanzolini e o escritor Dario Velloso. O primeiro estatuto do Instituto foi dividido em cinco capítulos: o primeiro trata dos fins e objetivos da instituição; o segundo estabelece a organização e eleição da diretoria; no terceiro capítulo o estatuto trata dos sócios, dividindo-os entre fundadores, efetivos, beneméritos, honorários, correspondentes e auxiliares; no capítulo quatro, são estabelecidas as regras para a publicação do material selecionado e produzido pelo Instituto. Por fim, no quinto capítulo estão as disposições gerais em que fica estabelecido que o Instituto deva formar uma galeria com retratos ou busto de paranaenses considerado por eles como “notáveis pela acção decisiva no progresso na civilização do Estado", uma homenagem que deverá ser póstuma, salvo exceções discutidas em sessões.

Em relação ao estatuto, destaca-se seu primeiro capítulo, intitulado DOS FINS DO INSTITUTO, seu único artigo seguido por dez parágrafos que definem a instituição.

\section{CAPITULO I}

\section{DOS FINS DO INSTITUTO}

Art. ${ }^{\circ} 1^{\circ}$ - O "Instituto Histórico e Geographico Paranaense" propõe-se:

$\S 1^{\circ}$ - A colligir, estudar, publicar e archivar os documentos que sirvam á historiographia do Paraná, promovendo a diffusão do seu conhecimento pela imprensa e pela tribuna; (BOLETIM DO IHGP, 1917, p.17-18).

Seguindo os preceitos positivistas e iluministas da época, o conhecimento válido era aquele produzido a partir de métodos e técnicas científicas, baseado em pesquisas, dados e provas. Nesse sentido, 
toda história escrita deveria ter a maior quantidade de comprovações possíveis, tais como relatos de viajantes e documentos oficiais.

De todos os objetivos que os institutos historiográficos possam ter, o principal é a coleta de dados e documentos sobre a região a qual eles se propõem dedicar e, a partir de então, produzir estudos e a divulgálos. As questões que se impõem são quais documentos e qual história é a escrita correta. Toda coleta e produção dependem dos indivíduos que os fazem e esses não estão isolados dos contextos sociais, históricos e políticos.

$\S 2^{\circ}$ - A promover excursões scientificas aos sítios aonde existam curiosidades naturaes, descrevendo-as e fazendo-as estudar por competentes;

$\S 3^{\circ}$ - A crear um museu ethnográphico; (BOLETIM DO IHGP, 1917, p.17-18)

Os parágrafos dois e três do estatuto não puderam ser realizados pelo Instituto por falta de orçamento e estrutura material. As dificuldades financeiras acompanharam a instituição paranaense durante anos. No entanto, muitos de seus membros partiram em missões pelo Paraná para fazer pesquisas em nome do estado, ou devido as suas funções políticas. Um deles foi Romário Martins, que viajou para São Paulo e Rio de Janeiro em busca de documentos que reafirmassem as fronteiras do Paraná com os estados limítrofes de São Paulo e Santa Catarina.

A publicação oficial do IHGP nos seus primeiros anos denomina-se "Boletins do Instituto Histórico e Geográfico Paranaense". Entre os anos de 1917 e 1925 foram publicados 8 fascículos e 32 artigos. Algumas das principais publicações do Boletim são de expedições realizadas no Paraná, como os textos do doutor Euzébio Paulo de Oliveira, produzidos quando este foi enviado pelo Serviço Geológico e Mineralógico do Brasil ao Paraná para verificar as possibilidades de extração de petróleo e minério de carvão.

As pesquisas sobre etnografia também estiveram presentes entre as publicações dos Boletins. Portanto, ainda que não tenham sido alcançados plenamente, os dois objetivos do IHGP foram abordados.

$\S 4^{\circ}$ - A organizar e manter o Archivo Publico creado pelo art. II das "Disposições Transitórias" da Constituição do Estado e cedido ao Instituto por officio n. 256, de 15 de junho deste anno, do exmo. Sr. Dr. Secretário do Interior, Justiça e Instrucção Publica;

$\S 5^{\circ}$ - A reorganizar e expor á freqüência publica a "Biblioteca do Estado", catalogando-a convenientemente, zelando-a e procurando obter-lhe o maior número de livros. (BOLETIM DO IHGP, 1917, p.17-18) 
O Arquivo Público foi fundado pelo Conselheiro Zacarias de Góes e Vasconcellos em 1855, para arquivar documentos históricos e geográficos da região, funcionando até 1889 no Palácio da Presidência da província. Como o IHGP, o Arquivo Público também sofreu com problemas estruturais que impossibilitaram suas pesquisas e publicações. Em 1909 o Arquivo Público passou a ser subordinado diretamente à Secretaria do Interior, Justiça e Instituição Pública, responsável pela sua manutenção, através da Repartição de Estatística e Arquivo Público do Paraná. Com a fundação da Biblioteca do Estado em 1859, hoje conhecida como Biblioteca Pública do Paraná, o processo foi similar, pois seus idealizadores, sem condições de concretizar aquilo que fora estabelecido, dependeram do apoio do estado para sua manutenção.

Apesar de terem objetivos bastante parecidos, O IHGP e o Arquivo Público não chegaram a rivalizar, pois o Arquivo exerce funções burocrático-estatais de armazenar documentos oficiais e dados diversos sobre o estado, enquanto o IHGP está voltado para questões historiográficas.

$\S 6^{\circ}$ - A remetter ao "Instituto Histórico e Geographico Brazileiro", no fim de cada anno, os documentos que pode obter com referencia á história e geographia de outros Estados, para o que os archivará convenientemente e lhes dará inserção na Revista si se referirem também ao Paraná. A relação de taes documentos, bem como o recibo que deverá ser passado pelo "Instituto Histórico e Geographico Brazileiro" accusando o seu recebimento, deverão constar do "Expediente" da Revista. (BOLETIM DO IHGP, 1917, p.17-18)

$\mathrm{O}$ artigo sexto revela que as relações entre a instituição nacional e a instituição regional não eram apenas no campo da inspiração. A preocupação na constituição e manutenção de vínculos com o IHGB, reportando os documentos coletados e as pesquisas feitas, também é um processo contínuo de revalidação e de legitimação do IHGP. Da mesma maneira, essa ligação normativa revela a subordinação existente do projeto regional de construção da História Oficial em relação ao projeto maior, nacional. A presença de sócios do IHGP no IHGB também é uma maneira de demonstrar o vínculo entre ambas. Romário Martins, o principal nome da instituição paranaense e um dos principais intelectuais e fomentadores do período, foi membro do IHGB.

$\S 7^{\circ}$ - A publicar uma Revista contendo a maior cópia possível de estudos e dados historiographicos e geographicos do Paraná e bem assim as actas e demais expedientes do Instituto; (BOLETIM DO IHGP, 1917, p.17-18) 
As publicações são importante instrumento destas instituições para que seus objetivos de construção da história, o resgate de um passado. No entanto, isso só será possível a partir de 1917 com a criação dos Boletins do IHGP.

$\S 8^{\circ}$ - A manter prelecções cívicas nas escolas públicas;

$\S 9^{\circ}$ - A commemorar as principaes datas da História Paranaense;

$\S 10^{\circ}$ - A instituir nas sessões a leitura de memórias, propostas de questões, etc. (BOLETIM DO IHGP, 1917, p.17-18)

A partir do primeiro capítulo do estatuto, é possível perceber que o IHGP está comprometido com dois projetos: um científico e outro cívico. O compromisso com a ciência, está representado a partir da coleta de dados e documentos, analisados e estudados pelos seus membros. O compromisso cívico está em sua relação com o estado do Paraná, a consolidação de suas instituições e a construção de outras que pudessem servir para melhor posicioná-lo frente aos demais estados brasileiros.

Também faz parte do compromisso cívico a sua relação com o Estado Brasileiro, representado pelo IHGB. Como exposto nos parágrafos $8^{\circ}, 9^{\circ}$ e $10^{\circ}$, há um compromisso expresso com a Pátria, ou seja, com o dever cívico junto aos demais cidadãos paranaenses e brasileiros.

\section{OS TRINTA PRIMEIROS ANOS DO IHGP}

Apesar das diversas reorganizações pelas quais passou a instituição de sua fundação até 1930, seu estatuto apenas sofreu alteração em 1948, quando em Assembleia foram aprovadas as modificações que possibilitaram a escolha de Romário Martins como patrono da instituição e seu presidente perpétuo, bem como a primeira mudança de seu nome para Instituto Histórico Geográfico e Etnográfico Paranaense. A segunda mudança significativa o correu em 1999, quando em Assembleia Geral Extraordinária foi alterado o nome da instituição para Instituto Histórico e Geográfico do Paraná e foi aprovado o Estatuto Social vigente atualmente (BLEY JR., 2000, p.175-176).

\footnotetext{
${ }^{6}$ A questão etnográfica no instituto paranaense necessita ser aprofundada. A influência da etnografia, como área de conhecimento, esteve presente na fundação do IHGP, conforme demonstra seu estatuto, mas foi suprimida do nome da instituição. É possível que as pesquisas feitas por Loureiro Fernandes tenham influenciado a mudança do nome na 
Idealizado e realizado por Alfredo Romário Martins, o IHGP teve como primeiro presidente o general José Bernardino Bormann, entre os anos de 1900 a 1905. Militar, vice-presidente do estado, considerado herói de guerra, Bormann produziu textos sobre a guerra do Paraguai e a revolução do estado de 1893. Foi aprovado na sua gestão o Estatuto Social em Assembleia Geral, ainda em 1900. A ausência de atividades fez com que no final de 1905 o Instituto fosse "desmantelado", como revela o documento "Notícia Histórica da Fundação do Instituto", publicado no primeiro Boletim do IHGP de 1917.

Insatisfeito com a inatividade da instituição, Romário Martins convocou os fundadores e membros para uma reunião na Biblioteca do Paraná (atual Biblioteca Pública do Paraná), no dia 24 de maio de 1906, com o objetivo de reativar o IHGP. Através da sugestão de João Pernetta, o próprio Romário Martins faz as indicações dos nomes para membros da nova diretoria, que teve como presidente Joaquim Procópio Pinto Chichorro Junior, entre 1906 a 1911. Advogado, jornalista e político, Chichorro foi deputado estadual e por várias vezes ocupou cargos nas secretarias do estado. No entanto, não conseguiu diminuir a apatia e falta de atividades do IHGP, que quase levaram a instituição ao fim.

No dia 30 setembro de 1911 uma nova Assembleia foi convocada na Biblioteca do Paraná. Nas duas primeiras reuniões, Romário Martins pediu para que não figurasse entre os candidatos à presidência, tendo ocupado o cargo de primeiro secretário nas gestões anteriores. Contudo, em 1911, Martins é eleito presidente do IHGP, com mandato até 1916.

No dia 23 de julho de 1916, uma nova reunião foi feita no Clube Curitibano a pedido de Ermelino de Leão que, por carta, solicitou a reorganização do IHGP. É a partir dessa nova constituição, tendo Marins Alves de Camargo como presidente e Romário Martins como vice, que teve início a publicação oficial do Instituto, o Boletim do IHGP.

No ano de 1919 houve mais uma reunião no Clube Curitibano, em que foram eleitos: Caetano Munhoz da Rocha, médico e político, como presidente de honra; José Francisco da Rocha Pombo como presidente honorário perpétuo; e João Moreira Garcez, como presidente efetivo. Essa gestão encerrou-se em 1925, quando a instituição é novamente silenciada.

Onze anos mais tarde, no dia 24 de maio de 1945, na residência de Romário Martins, é feita a última e definitiva reunião de reorganização da instituição. A partir de então, ela passa a ser chamada de Instituto Histórico Geográfico e Etnográfico Paranaense, ao qual foi integrado o núcleo curitibano da Associação dos Geógrafos Brasileiros. Nesta cerimônia, Romário Martins é aclamado como seu presidente perpétuo, função que exerceu até sua morte, quando foi elevado ao status de patrono do Instituto, em 1948.

década de 40 e as transformações no campo das ciências tenha levado seus sócios a suprimirem novamente o etnográfico no nome do instituto no final do século XX. 
Muitas foram as dificuldades estruturais do IHGP, que não contava com sede nem recursos próprios nos seus primeiros anos de existência. Entre 1900 a 1930, o Instituto utilizou como sede a Biblioteca do Paraná, as dependências do Clube Curitibano e a residência de Romário Martins, na Rua Cruz Machado, número 269. A partir de 1948, o Instituto alocou-se junto ao Circulo de Estudos Bandeirantes, até receber de doação da prefeitura de Curitiba, em 1953, o terreno na rua José Loureiro, onde foi construída sua sede permanente ocupada desde 1959.

As palavras proferidas por Romário Martins na fundação da instituição parecem prever as dificuldades que o IHGP iria encontrar desde 1900 até a sua última reorganização, em 1945. De 1900 a 1925 , foram 5 gestões e 4 tentativas de revitalização, que poucos resultados trouxeram além das primeiras publicações do Boletim do IHGP. Mesmo assim, a ideia continuou viva entre alguns poucos entusiastas.

\section{CONSIDERAÇÕES FINAIS}

A instituição paranaense exerceu um importante papel de respaldo científico a produção intelectual de seus membros, ainda que não tenha sido um ambiente de desenvolvimento de pesquisas e de discussões, ainda que as poucas publicações produzidas revelem características importantes do pensamento paranaense no período estudado.

Durante os seus primeiros trinta anos, o IHGP exerceu a função simbólica de representar a inserção do Paraná no mundo dos estudos científicos, servindo de suporte institucional para a produção de seus membros e fundadores.

Lílian Schwarcz (1993, p.104-105) afirma, em seu estudo sobre o IHGB no século XIX, que seus membros eram políticos e proprietários de terra, que tinham na instituição um ambiente de consagração do grupo dominante local e de uma história regional. "A associação cumpria, assim, diferentes papéis: para alguns significava um local de projeção intelectual, para outros um espaço de promoção pessoal”. No Panará, a função do IHGB foi semelhante. 


\section{REFERÊNCIAS}

BEGA, Maria Tarcisa Silva. Sonho e invenção do Paraná: geração simbolista e a construção da identidade regional. São Paulo, USP, 2001, pp. 444. Tese (Doutorado em Sociologia) - Faculdade de Filosofia, Letras e Ciências Humanas da Universidade de São Paulo.

BLEY JR., Waldemiro. "O nosso instituto". In: Boletim do Instituto histórico e Geográfico do Paraná, Curitiba, Imprensa Oficial, 2000, vol.LI, pp.175-176.

CALLARI, Cláudia Regina. "Os Institutos Históricos: do Patronato de D. Pedro II à construção do Tiradentes". In: Revista Brasileira de História, São Paulo, 2001, v.21, n.40, p.59-83.

CAMARGO, Geraldo Leão Veiga de. Paranismo:arte, ideologia e relações sociais no Paraná. 1853-1953. Curitiba, UFPR, 2007, pp.215. Tese (Doutorado em História) - Setor de Ciências Humanas, Letras e Artes da Universidade Federal do Paraná.

CASTORIADIS, Cornelius. A instituição imaginária da sociedade. Rio de Janeiro, Paz e Terra, 1982.

GUIMARÃES, Manoel Luís Salgado. "Nação e Civilização nos Trópicos: o Instituto Histórico e Geográfico Brasileiro e o Projeto de uma História Nacional". In: Estudos Históricos, Rio de Janeiro, n.1, 1988. p.5-27.

KEINERT, Ruben Cesar. Regionalismo e anti regionalismo no Paraná. São Paulo, USP, 1979, pp.124. Dissertação (Mestrado em História) - Faculdade de Filosofia, Letras e Ciências Humanas da Universidade de São Paulo.

LOVE, Joseph L. Federalismo y regionalismo en Brasil, 1889-1937. In: CARMAGNANI, Marcello (cord.). Federalismos latinoamericanos: México, Brasil, Argentina. México, Fondo de Cultura Económica, 1993. p.180-223.

OLIVEIRA, Ricardo Costa de. O silêncio dos vencedores: genealogia, classe dominante e Estado do Paraná. Curitiba, Moinho do Vento, 2001.

PEREIRA, Luis Fernando Lopes. Paranismo: o Paraná inventado. Curitiba, Aos Quatro Ventos, 1998.

PILATTI BALHANA, A; PINHEIRO MACHADO, B; WESTPHALEN, C. História do Paraná: vol. 1. Curitiba, Grafipar, 1969.

SALTURI, Luis Afonso. Frederico Langes de Morretes, liberdade dentro de limites: trajetória do artista cientista. Curitiba, UFPR, 2007, pp. 268. Dissertação (Mestrado em Sociologia) - Setor de Ciências Humanas, Letras e Artes da Universidade Federal do Paraná.

SCHWARCZ, Lilia Moritz. O espetáculo das raças: cientistas, instituições e questão racial no Brasil 18701930. 5. reim. São Paulo, Cia das Letras, 2005.

SZVARÇA, Décio. O forjador: ruínas de um mito - Romário Martins. 2. ed. Curitiba, Aos Quatro Ventos, 2004.

TRINDADE, Etelvina Maria de Castro. "Paranidade ou Paranismo? A construção de uma identidade regional”. In. Revista da SBPH. n.13 Curitiba, 1997, p.65-74. 


\section{DOCUMENTO CONSULTADO:}

ESTATUTO do Instituto Histórico e Geográfico Paranaense. In BOLETIM do Instituto Histórico e Geográphico Paranaense, Curitiba, 1917, v.1, n.1, p.17-19.

INSTITUTO HISTÓRICO E GEOGRÁPHICO PARANAENSE. "Notícia Histórica da Fundação do Instituto". In: BOLETIM do Instituto Histórico e Geográphico Paranaense, Curitiba, 1917, v.1, n.1, p.5-13.

\section{THE EARLY YEARS OF PARANÁ HISTORIC AND GEOGRAPHIC INSTITUTE (1900-1930)}

\footnotetext{
ABSTRACT

The Paraná Historic and Geographic Institute (IHGP) was founded in 1900, from the political-economic and sociocultural situations present in the Paraná of the early twentieth century that sought, among other objectives, to build a regional imaginary able to integrate the thousands of immigrants newcomers from Europe to Paraná society. From the perspective of the social imaginary of Cornelius Castoriadis (1982), the article's objectives are to think about the foundation of IHGP, from your statute, and present a history of the first thirty years of existence.
}

Key-words: IHGP, regional imaginary, XX century. 